\title{
Evidence of Induced Systemic Resistance Against Botrytis elliptica in Lily
}

\author{
Yi-Hung Liu, Chien-Jui Huang, and Chao-Ying Chen
}

Department of Plant Pathology and Microbiology, National Taiwan University, No. 1, Sec. 4, Roosevelt Rd., Taipei 10617, Taiwan, Republic of China.

Accepted for publication 18 February 2008.

\section{ABSTRACT}

Liu, Y.-H., Huang, C.-J., and Chen, C.-Y. 2008. Evidence of induced systemic resistance against Botrytis elliptica in lily. Phytopathology 98:830-836.

Lily leaf blight, caused by Botrytis elliptica, is an important fungal disease in Taiwan. In order to identify an effective, nonfungicide method to decrease disease incidence in Lilium formosanum, the efficacy of rhizobacteria eliciting induced systemic resistance (ISR) was examined in this study. Over 300 rhizobacteria were isolated from the rhizosphere of L. formosanum healthy plants and 63 were identified by the analysis of fatty acid profiles. Disease suppressive ability of 13 strains was demonstrated by soil drench application of bacterial suspensions to the rhizosphere of L. formosanum seedlings. Biocontrol experiments were carried out with Bacillus cereus and Pseudomonas putida strains on L. formo- sanum and Lilium Oriental hybrid cvs. Acapulco and Star Gazer in greenhouse and field studies. Plants treated with $B$. cereus strain C1L showed that protection against $B$. elliptica on $L$. formosanum could last for at least 10 days and was consistent with high populations of B. cereus on lily roots. Analysis of the expression of LfGRP1 and LsGRP1, encoding glycine-rich protein associated with $L$. formosanum and cv. Star Gazer, respectively, revealed different responses induced by $B$. cereus or by the pathogen $B$. elliptica, suggesting that plant defense responses elicited by each follows a different signaling pathway. According to the results of biocontrol assays and LfGRP1/LsGRP1 gene expression analyses with culture filtrates of $B$. cereus strain $\mathrm{C} 1 \mathrm{~L}$, we propose that eliciting factors of ISR are generated by B. cereus and some of them exhibit thermostable and heat-tolerant traits. This is the first report about ISR-eliciting rhizobacteria and factors effective for foliar disease suppression in lily.
Botrytis leaf blight, caused by the fungal pathogen Botrytis elliptica (Berk.) Cooke, is one of the most important diseases of lilies (Lilium spp.) in Taiwan $(2,13,19)$. Fungicides have been frequently used to control the disease in cut flower production, but effectiveness is limited due to the rapid development of fungicide resistance in B. elliptica $(4,22)$. Other methods have shown potential to control Botrytis leaf blight of lily. Both Bacillus amyloliquefaciens B190 (5) and Bacillus cereus 28-9 (14), applied as foliar applicants, have shown effective in biologically controlling the disease. Similarly, systemic resistance activated by application with salicylic acid (SA) and probenazole has been demonstrated to be effective against lily leaf blight in Lilium Oriental hybrid cv. Star Gazer (16-18).

Biotic or abiotic factors can alter physiological or biochemical responses of plants to invoke multiple complex defense mechanisms. The biotic induction of plant responses by interactions with pathogenic or nonpathogenic microorganisms can result in systemic resistance responses referred to as systemic acquired resistance (SAR) $(8,38)$ and induced systemic resistance (ISR) $(1,15,29,40)$, respectively. Induction of SAR or ISR is elicited through different signaling pathways $(27,45)$. However, enhanced resistance effective against a broad spectrum of plant pathogens, including fungi, bacteria, viruses, nematodes, and even insect herbivores, is a general phenomenon of systemic resistance triggered by different kinds of factors $(38,40,46)$. Both kinds of induced resistances enhance plant innate defenses against subsequent biotic challenges (40). In the early state after pathogen

Corresponding author: C.-Y. Chen; E-mail address: cychen@ntu.edu.tw

*The $\boldsymbol{e}$-Xtra logo stands for "electronic extra" and indicates that Figure 3 appears in color online.

doi:10.1094/PHYTO-98-7-0830

(c) 2008 The American Phytopathological Society attack, accumulation of endogenously synthesized SA triggers SAR activity $(20,21)$, followed by the activation of genes encoding pathogenesis-related (PR) proteins $(39,43)$. As demonstrated in Arabidopsis thaliana, prevention of SA accumulation by transgenic expression of $n a h G$ encoding for salicylate hydroxylase, results in no increased expression of $P R$ gene and SAR activation, showing that SA is an important factor in the SAR signaling pathway (9). Since methyl salicylate (MeSA) esterase activity of the SA-binding protein 2 (SABP2) of tobacco can convert MeSA into SA, Park et al. inferred that MeSA acts as a crucial signal of SAR in tobacco (26). In contrast to SAR, ISR triggered in A. thaliana by Pseudomonas fluorescens WCS417r does not cause SA accumulation and PR gene expression, but instead requires the plant hormones jasmonic acid and ethylene to induce resistance in plants (27).

In previous studies, molecular analysis of gene expression in response to SA treatment in Oriental lily cv. Star Gazer identified a cDNA sequence encoding a 138-amino acid protein by suppression subtractive hybridization (17). This putative protein designated LsGRP1 shared homology with several glycine-rich proteins present in the plant extracellular matrix (17). Northern blot analysis detected an increase of LsGRPl-related mRNA in 'Star Gazer' leaves after SA treatment, and also in B. elliptica-infected and upper uninoculated leaves. When B. elliptica was inoculated onto SA-treated leaves, accumulation of LsGRPl-related mRNA appeared earlier compared with that without SA treatment, suggesting a possible role for LsGRP1 in the SAR in lily (17).

Lilium formosanum Wall. (Formosa lily) is a native lily species of Taiwan that is widely distributed mostly as a wild plant, but is also used for landscaping purposes $(33,44)$. In 2003, an outbreak of Botrytis leaf blight severely devastated L. formosanum in Pulowan, Taroko National Park in Hua-lien, Taiwan. Based on previous observations demonstrating the potential of systemic resistance to control lily leaf blight in Lilium Oriental hybrid cv. 
Star Gazer (16-18), we examined whether ISR triggered by nonpathogenic rhizobacteria would be a good strategy to protect $L$. formosanum from infection by B. elliptica. To approach this goal, a screening experiment was performed to identify promising rhizobacteria from the rhizosphere of healthy L. formosanum and test their abilities to suppress Botrytis leaf blight on different kinds of lilies. In addition, we were interested in determining if glycine-rich proteins were associated with ISR in Lilium species. These results provide further insight into the mechanisms underlying SAR and ISR, especially in the monocot lily. In addition, characterization of the eliciting factor(s) of ISR was approached in the ISR-eliciting rhizobacterium B. cereus strain CIL.

\section{MATERIALS AND METHODS}

Bacterial and fungal strains and inocula preparation. The roots with least adhered soils were excised from $L$. formosanum plants appearing healthy in the landscape area of Pulowan, Taroko National Park in Hua-lien, Taiwan, and were subsequently stirred in sterile water for $30 \mathrm{~min}$. Serial dilutions of bacterial suspensions were plated on Difco nutrient agar (Becton Dickinson) and incubated at $28^{\circ} \mathrm{C}$. Isolates were purified to single colonies on Luria-Bertani (LB) agar medium (1\% tryptone, $0.5 \%$ yeast extract, $0.5 \% \mathrm{NaCl}$, and $1.5 \%$ agar). Bacterial inocula for applications on plants were prepared by culturing strains in LB broth at $28^{\circ} \mathrm{C}$ for $16 \mathrm{~h}$. Bacterial cells were harvested by centrifugation $(4,000 \times g, 10 \mathrm{~min})$ and suspended in $10 \mathrm{mM} \mathrm{MgSO}$ to a final concentration of $1 \times 10^{8}$ colony forming units $(\mathrm{CFU}) / \mathrm{ml}$. A solution of $10 \mathrm{mM} \mathrm{MgSO}$ with no bacteria was used as a negative control.

B. elliptica strain B061-1 (17) was used for all experiments. Inoculum was prepared by growing the strain on V8 agar $(20 \%$ V8 vegetable juice [Campbell soup group], $0.3 \% \mathrm{CaCO}_{3}$, and $1.5 \%$ agar) under near-UV light for 5 days $(7,17,18)$. Conidia were collected by gently vortexing in Tween 20 solution $(0.05 \%$ Tween 20 in sterile deionized water) and adjusted to a concentration of $5 \times 10^{4}$ conidia $/ \mathrm{ml}$ as inoculum.

Identification of bacterial strains. Bacterial isolates were purified to single colonies several times on LB agar and identified by analysis of fatty acid profiles with the Microbial Identification System (MIDI, Inc., Newark, DE) following the protocol of Microbial Identification System, in that MIDI Sherlock software (version 5.0; MIDI, Inc.) coupled with ChemStation software (version 4.02; Hewlett-Packard, Avondale, PA). B. cereus 28-9 (14), a known strain from our lab, was used for comparison with new isolates.

Plant cultivation. For greenhouse studies, L. formosanum seedlings were grown in $7.5 \mathrm{~cm}$ pots (one seedling per pot) and the bulbs of Oriental lily cv. Star Gazer were grown in $14 \mathrm{~cm}$ pots (one bulb per pot) using potting mix consisting of peat moss and perlite at a ratio of $3: 1$. Plants were grown at 20 to $25^{\circ} \mathrm{C}$ with a cycle of $12 \mathrm{~h} / 12 \mathrm{~h}$ light/dark for 30 to 45 days. For field assays, $L$. formosanum and Oriental lily cvs. Star Gazer and Acapulco plants were grown in the soil with individual plants 3.5 to $4 \mathrm{~cm}$ apart. Bacterial treatment began about 30 days after planting. The soil of sand-loam type was planted. Irrigation was applied by drenching twice a week.

Screening of bacterial strains based on ISR-eliciting potential and effect on plant growth. For screening the bacterial strains capable of eliciting ISR, the rhizosphere of L. formosanum seedling was drenched with $30 \mathrm{ml}$ of bacterial suspension at 10-day intervals three times. B. elliptica was inoculated 4 days after the last bacterial application by atomizing conidial suspensions onto the abaxial surface of lily leaves until dripping off the leaves.

The extent of lesion development was scored 4 days after inoculation based on a disease rating scale from 0 to 4 , in which $0=$ no lesions; $1=$ less than $12 \%$ of leaf area with lesions; $2=13$ to $25 \%$ of leaf area with lesions; $3=26$ to $50 \%$ of leaf area with lesions; and $4=$ more than $50 \%$ of leaf area with lesions. Each treatment consisted of five plants and three leaves in each plant were inoculated. The effect of bacterial treatments on the growth of lily seedlings was assessed based on the alteration of leaf number.

Biological control assays. Biocontrol assays were performed in greenhouse conditions at National Taiwan University and under field conditions at Hua-lian, Taipei, and I-lan in North Taiwan. Bacterial strains tested included those selected from the rhizosphere of L. formosanum plants and B. cereus $28-9$, a previously identified strain that demonstrated potential as a foliar applied biocontrol agent against B. elliptica (14). L. formosanum seedlings were used in the greenhouse assay. All other studies used adult plants. The rhizosphere of lily seedling was drenched with $30 \mathrm{ml}$ of bacterial suspension, but $50 \mathrm{ml}$ was used for adult lily plants. The time schedules of bacterial application were set as follows: (i) three times at 10-day intervals for greenhouse assay; (ii) eight times at 14-day intervals for L. formosanum plants in field studies; and (iii) three times at 10- and 14-day intervals for 'Star Gazer' and 'Acapulco', respectively, in field studies. $B$. elliptica was inoculated 4 days after the last bacterial application. The extent of lesion development on L. formosanum was scored based on a disease rating scale as described above, and the lesion number on Oriental lily was assessed. In the greenhouse assay on L. formosanum, each treatment consisted of five plants with three leaves per plant inoculated with the pathogen. Each treatment on Oriental lily cv. Star Gazer consisted of 10 plants, with three leaves of each plant inoculated with the pathogen. In field assays, each treatment consisted of 25 plants with five leaves per plant being inoculated. All experiments were repeated twice.

Bioassay of ISR-eliciting potential of B. cereus. To show the periods of ISR expression triggered by $B$. cereus, the rhizosphere of $L$. formosanum seedling was drenched with $30 \mathrm{ml}$ of bacterial suspension on different days before fungal inoculation. The extent of lesion development was scored 4 days after fungal inoculation based on a disease rating scale as described above. Each treatment consisted of five plants with three leaves from each plant inoculated with the pathogen. The experiment was repeated twice.

In vivo rhizosphere colonization assay. Rhizosphere colonization ability of $B$. cereus strain $\mathrm{C} 1 \mathrm{~L}$ was studied using a rifampicin-resistant marker strain on the roots of $L$. formosanum seedlings. The rifampicin-resistant strain of B. cereus was isolated on LB medium containing rifampicin (100 $\mathrm{mg} / \mathrm{liter})$ according to the method previously described (28). Bacterial suspensions of the rifampicin-resistant strain were applied to the rhizosphere of lily seedlings as a soil drench (30 $\mathrm{ml}$ each). Rhizosphere samples were taken each day after suspensions were applied for the first 5 days, followed by samplings on 7 and 10 days after application. The top $1 \mathrm{~cm}$ of root, beginning from the stem, was dissected from three roots from each lily seedling and suspended in $1 \mathrm{ml}$ of sterile water with vortexing for $10 \mathrm{~min}$. Three seedlings were assessed at each time period after bacterial application. The suspension of root segments of a seedling was subjected to appropriate dilutions and plated on LB medium containing rifampicin (100 mg/liter). After growing overnight at $28^{\circ} \mathrm{C}$, the number of bacteria on the root (per centimeter) at each time period after bacterial application was measured.

Assay of ISR-eliciting factors possibly produced by $B$. cereus. For investigation on the ISR-eliciting factors produced by $B$. cereus strain $\mathrm{C} 1 \mathrm{~L}$, the rhizosphere of lily cv. Star Gazer was drenched with $B$. cereus culture filtrate, followed by fungal inoculation at 1, 4, and 7 days after pretreatment. Treatments consisted of (i) B. cereus strain $\mathrm{C} 1 \mathrm{~L}$ cell-free culture filtrates (through $0.45 \mu \mathrm{m}$ filter) from $50 \mathrm{ml}$ of $16 \mathrm{~h}$ culture in LB broth; (ii) $B$. cereus strain $\mathrm{C} 1 \mathrm{~L}$ culture filtrates autoclaved for $10 \mathrm{~min}$; and (iii) uninoculated LB medium as a control. Each treatment consisted of five plants, with five inoculated leaves per plant. Three days 
after fungal inoculation, lesion numbers were recorded. The experiment was repeated twice. In addition, B. cereus 28-9 was used as another test strain.

Cloning of LsGRP1 homolog from L. formosanum. In order to analyze the gene expression in response to bacterial application in the rhizosphere of lily plants, a cDNA homolog of the known SA-, probenazole-, and pathogen-inducible LsGRPl of Oriental lily cv. Star Gazer $(17,18)$ was cloned from L. formosanum and used as one of the DNA probes in northern blot hybridization analysis. Total RNA of the leaves of $L$. formosanum $48 \mathrm{~h}$ after inoculation with B. elliptica was extracted by a Plant Total RNA Extraction Miniprep System (Viogene, Sunnyvale, CA) and used to synthesize the cDNAs with PowerScript Reverse Transcript Kit (BD Bioscience Clontech, Heidelberg, Germany). Primers (5'CCAAGGATCCGGTCGGGAGCTGGCTGAGGAAC-3', 5'-CCAAGAATTCTTATGGGTGTCCATAAGCAGGCTC-3') were designed according to the cDNA sequence of $L s G R P 1$ of Oriental lily cv. Star Gazer (accession no. AY072283) and used in the subsequent polymerase chain reaction (PCR) amplification of the LsGRP1 homolog. The DNA fragments from reverse transcription-PCR were cloned into pGEMT easy vector (Promega, Madison, WI) and the resulting plasmids were transformed into Escherichia coli DH5 $\alpha$ (Bethesda Research Laboratories). DNA sequencing was carried out with BigDye terminator cycle sequencing ready reaction in $\mathrm{ABI} 310$ DNA sequencer (PerkinElmer). Sequence data were analyzed for homology to LsGRP1 using the basic local alignment search tool in the Blast program (provided online by the National Center for Biotechnology Information).

Northern blot hybridization analysis. The rhizosphere of lily plants was drenched with an equivalent amount of either $B$. cereus bacterial suspension $\left(1.0 \times 10^{8} \mathrm{CFU} / \mathrm{ml}\right)$ or the culture filtrate at different periods before harvest. Suspensions of 30 and $50 \mathrm{ml}$ were used for L. formosanum seedling and lily cv. Star Gazer plant, respectively. The leaves were detached and stored at $-80^{\circ} \mathrm{C}$ until extraction. Total RNA of lily leaves was extracted and separated on $1 \%$ agarose gel prepared in $2.2 \mathrm{M}$ formaldehyde-containing $1 \times$ MOPS buffer (40 mM MOPS, pH 7.0, $10 \mathrm{M}$ sodium acetate, and $1 \mathrm{mM}$ EDTA), using $1 \times$ MOPS running buffer. The membrane was UV cross-linked and hybridized with the respective digoxigenin (DIG)-labeled DNA probe that was prepared using PCR DIG Probe Synthesis Kit (Roche Diagnostics, Mannheim, Germany). Hybrids were detected with the DIG Luminescent Detection Kit for nucleic acids (Roche Diagnostics). In addition, lily leaves were inoculated with $B$. elliptica 1 day after application of bacterial suspension or culture filtrate, or without pretreatment, and examined for alteration in the amount of corresponding mRNA transcript.
Statistical analysis. The data obtained were subjected to the standard analysis of variance (ANOVA) procedure. Least significant difference values at $P=0.05$ were used to separate treatment means when ANOVA indicated a significant $F$ value.

\section{RESULTS}

Screening rhizobacteria isolated from the rhizosphere of $\boldsymbol{L}$. formosanum for ISR-eliciting potential and positive effect on seedling growth. Over 300 bacteria were isolated from the rhizosphere of L. formosanum plants collected from Pulowan, Taroko National Park in Hua-lien, Taiwan. Sixty-three bacteria were identified by gas chromatography analysis of fatty acid methyl esters (Table 1). Bacillus and Pseudomonas species comprised 28 and $38 \%$ of all identified strains, respectively. The greenhouse screening test on L. formosanum seedlings showed that at least 13 bacterial strains were capable of decreasing lesion development on the leaves caused by $B$. elliptica when bacterial suspensions were applied to the rhizosphere. Among them, many showed a positive effect on plant growth but some had an adverse effect on plant growth (Table 1).

Biocontrol assays. In this study, B. cereus strains $\mathrm{C} 1 \mathrm{~L}$ and A3S21 and P. putida strains CF-3 and CF2-1 were compared with the previously characterized biocontrol strain B. cereus 28-9 (14) for their ability to suppress disease on lily. As shown in Table 2,

TABLE 2. Disease suppression by rhizobacterial strains against Botrytis leaf blight of Lilium formosanum ${ }^{\mathrm{y}}$

\begin{tabular}{lcc}
\hline & \multicolumn{2}{c}{ Disease index $^{\mathrm{z}}$} \\
\cline { 2 - 3 } Bacterial strain & Greenhouse assay & Field assay \\
\hline Bacillus cereus C1L & $0.8 \mathrm{bc}$ & $0.6 \mathrm{~d}$ \\
Bacillus cereus A3S21 & $1.3 \mathrm{~b}$ & $1.3 \mathrm{~b}$ \\
Bacillus cereus $28-9$ & $1.3 \mathrm{~b}$ & $0.8 \mathrm{~cd}$ \\
Pseudomonas putida CF-3 & $1.3 \mathrm{~b}$ & $0.9 \mathrm{bcd}$ \\
Pseudomonas putida CF2-1 & $1.6 \mathrm{~b}$ & $1.0 \mathrm{bcd}$ \\
Disease CK & $3.7 \mathrm{a}$ & $2.0 \mathrm{a}$ \\
Health CK & $0.0 \mathrm{c}$ & $0.0 \mathrm{e}$ \\
\hline
\end{tabular}

${ }^{y}$ Suspensions of rhizobacteria $\left(1 \times 10^{8} \mathrm{CFU} / \mathrm{ml}\right)$ were applied to the rhizosphere of lily plants three times at 10-day intervals in greenhouse assays, and eight times at 14-day intervals in field assay. Conidial suspensions of Botrytis elliptica were inoculated onto the abaxial surface of lily leaves 4 days after the final bacterial treatment.

${ }^{z}$ Values represent the average of disease index in a plant scored 4 days after fungal inoculation as described in the text. Greenhouse assay treatments consisted of five plants with three leaves inoculated per plant; field assay treatments consisted of 25 plants with five leaves inoculated per plant. Data in the same column followed by different letters are significantly different $(P=0.05)$.

TABLE 1. Bacterial strains isolated from Lilium formosanum rhizosphere and the screening tests

\begin{tabular}{|c|c|c|c|c|}
\hline Species & Number of isolates & Biocontrol seedling test ${ }^{\mathrm{y}}$ & Strains showing positive effect ${ }^{z}$ & Strains showing negative effect \\
\hline Acinetobacter calcoaceticus & 3 & A3S10; A3S9 & A3S10 & A3S9 \\
\hline Arthrobacter viscosus & 1 & & & \\
\hline Bacillus cereus & 8 & C1L; A3S21 & C1L; A3S21 & \\
\hline Bacillus pumilus & 2 & A3S11 & A3S11 & \\
\hline Brevibacillus choshimensis & 2 & A3S12; CF4-1-K & A3S12 & CF4-1-K \\
\hline Burkholderia cepacia & 7 & A3S36; CF4-4-2; CFQP & A3S36; CF4-4-2 & CFQP \\
\hline Delftia acidov & 1 & & & \\
\hline Pseudomonas agarici & 1 & & & \\
\hline Pseudomonas fluorescens & 2 & A2S1 & & A2S1 \\
\hline Pseudomonas putida & 11 & CF-3; CF2-1; CF3-1 & CF-3; CF2-1 & CF3-1 \\
\hline Pseudomonas syringae & 10 & & & \\
\hline Rhizobium radiobacter & 2 & & & \\
\hline Salmonella choleraesuis & 2 & & & \\
\hline
\end{tabular}


these strains could protect $L$. formosanum from Botrytis leaf blight in both greenhouse and field conditions. The ability of the five strains to suppress disease was further tested on Oriental lily cultivars. Results indicated that these strains were able to decrease lesion number caused by B. elliptica on Oriental lily cvs. Star Gazer and Acapulco in the greenhouse and field studies, with B. cereus C1L exhibiting the best biocontrol activity (Tables 2 and 3).

ISR-eliciting potential of $\boldsymbol{B}$. cereus. B. cereus strain C1L was assayed for ISR-eliciting activity and root colonization trait. Figure 1 indicates that a $40 \%$ reduction in disease severity could be achieved when $B$. cereus strain $\mathrm{C} 1 \mathrm{~L}$ bacterial suspension was applied to the rhizosphere of $L$. formosanum seedling 1 day before fungal inoculation. Such protection was further enhanced to $75 \%$ reduction of disease severity when the seedling was treated with $B$. cereus strain C1L bacterial suspension 4 or 5 days before fungal inoculation. About $70 \%$ of disease suppression could be maintained up to 10 days after bacterial application. To demonstrate the rhizosphere competence of B. cereus strain $\mathrm{C} 1 \mathrm{~L}$,

TABLE 3. Disease suppression by rhizobacterial strains against Botrytis leaf blight of Oriental lily cvs. Star Gazer and Acapulco ${ }^{y}$

\begin{tabular}{lcccc}
\hline & \multicolumn{3}{c}{ Number of lesions ${ }^{\mathrm{z}}$} \\
\cline { 2 - 3 } Bacterial strain & Greenhouse assay & & \multicolumn{2}{c}{ Field assay } \\
\cline { 2 - 3 } \cline { 5 - 6 } 'Star Gazer' & & 'Star Gazer' & 'Acapulco' \\
\hline Bacillus cereus C1L & $7.8 \mathrm{~b}$ & & $0.8 \mathrm{~d}$ & $2.6 \mathrm{c}$ \\
Bacillus cereus A3S21 & $6.8 \mathrm{bc}$ & & $6.5 \mathrm{ab}$ & $4.2 \mathrm{bc}$ \\
Bacillus cereus $28-9$ & $12.8 \mathrm{~b}$ & & $5.4 \mathrm{abc}$ & $4.5 \mathrm{bc}$ \\
Pseudomonas putida CF-3 & $11.6 \mathrm{~b}$ & & $4.9 \mathrm{abc}$ & $12.1 \mathrm{~b}$ \\
Disease CK & $10.4 \mathrm{~b}$ & & $4.3 \mathrm{bc}$ & $4.4 \mathrm{bc}$ \\
Health CK & $20.8 \mathrm{a}$ & & $8.1 \mathrm{a}$ & $25.2 \mathrm{a}$ \\
& $0.0 \mathrm{c}$ & & $0.0 \mathrm{~d}$ & $0.0 \mathrm{c}$ \\
\hline
\end{tabular}

${ }^{y}$ Suspensions of rhizobacteria were applied to the rhizosphere of lily plants three times at 10-day intervals for 'Star Gazer' and 14-day intervals for 'Acapulco'. Conidial suspensions of Botrytis elliptica were inoculated onto the abaxial surface of lily leaves 4 days after the last bacterial application. Lesion numbers were recorded 4 days after fungal inoculation.

${ }^{z}$ Values represent the average number of lesions on a leaf. Greenhouse assay treatments consisted of 10 plants with three leaves inoculated per plant; field assay treatments consisted of 25 plants with five leaves inoculated per plant. Data in the same column followed by different letters are significantly different $(P=0.05)$.

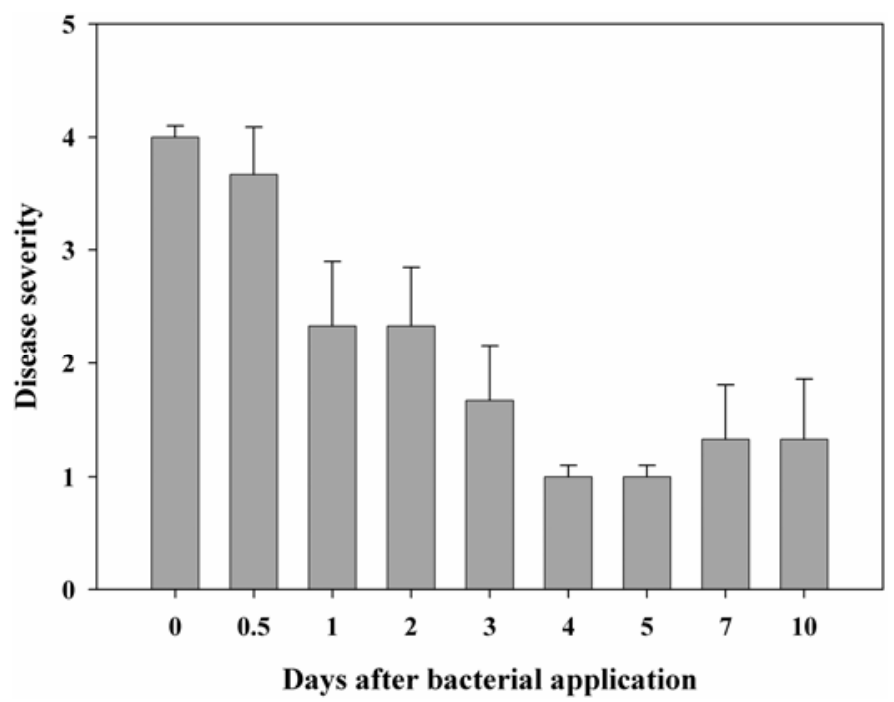

Fig. 1. Disease suppressing potential of Bacillus cereus strain C1L on Lilium formosanum over time. Fungal inoculation was performed different days after bacterial application to the rhizosphere of L. formosanum. Extent of lesion development was scored 4 days after fungal inoculation based on a disease rating scale. The value represents the average of disease index in a plant. Each treatment had five plants and three leaves in a plant were inoculated. Vertical bars indicate standard deviations of the mean. we used a rifampicin-resistant strain generated from $B$. cereus strain $\mathrm{C} 1 \mathrm{~L}$ to analyze bacterial colonization in the rhizosphere of $L$. formosanum seedlings. Results showed that B. cereus strain $\mathrm{C} 1 \mathrm{~L}$ populations were present at the top $1 \mathrm{~cm}$ of root beginning from the stem and that bacterial populations could be maintained at a level between $5 \times 10^{6}$ and $10^{5} \mathrm{CFU} / \mathrm{cm}$ up to 5 days after bacterial application. B. cereus strain $\mathrm{C} 1 \mathrm{~L}$ was still present in the basal portion of the lily root at populations above $10^{4} \mathrm{CFU} / \mathrm{cm}$ up to 10 days after application (Fig. 2).

Assay of putative ISR factors produced by $\boldsymbol{B}$. cereus. Table 4 shows the effect of culture filtrates of B. cereus strains C1L and 28-9 on the infection of 'Star Gazer' leaves by B. elliptica. The culture filtrates of both strains applied to the rhizosphere of lily plants could decrease lesion number caused by $B$. elliptica; effective protection was achieved 1 day after treatment. Equivalent levels of disease suppression were observed when the culture filtrates were applied 4 and 7 days before fungal inoculation. When the culture filtrates of both $B$. cereus strains were autoclaved, their abilities to protect lily cv. Star Gazer from infection by Botrytis elliptica were maintained, especially when application was done 4 and 7 days before fungal inoculation. On the other hand, when treatment was carried out just a day before fungal inoculation, the autoclaved culture filtrates of $B$. cereus strain C1L and B. cereus 28-9 displayed much lower levels of protection

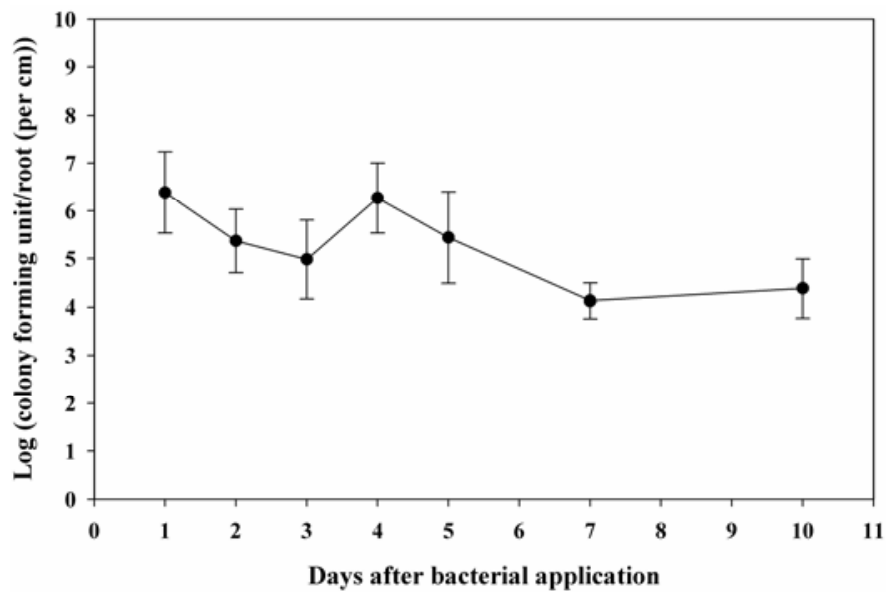

Fig. 2. Populations of Bacillus cereus strain $\mathrm{C} 1 \mathrm{~L}$ on the basal regions of Lilium formosanum roots over time. Value represents the mean of bacterial number from three root segments of a seedling. Different seedlings of three were used in each time point. Vertical bars represent standard deviations of mean values of bacterial number on the root $(\log$ (colony forming unit/root [per $\mathrm{cm}])$.

TABLE 4. Disease suppression caused by the treatment of culture filtrates of Bacillus cereus strains against Botrytis leaf blight of Oriental lily cv. Star Gazer

\begin{tabular}{lccccc}
\hline Period of & \multicolumn{4}{c}{ Number of lesion $^{\mathrm{z}}$} \\
\cline { 2 - 3 } $\begin{array}{l}\text { treatment } \\
\text { before fungal }\end{array}$ & \multicolumn{2}{c}{ B. cereus $28-9$} & & \multicolumn{2}{c}{ B. cereus $\mathrm{C} 1 \mathrm{~L}$} \\
\cline { 2 - 3 } \cline { 5 - 6 } inoculation $^{\mathrm{y}}$ & Un-autoclaved & Autoclaved & & Un-autoclaved & Autoclaved \\
\hline 1 day & $5.5 \mathrm{~b}$ & $13.5 \mathrm{a}$ & & $7.3 \mathrm{~b}$ & $13.9 \mathrm{a}$ \\
4 days & $7.5 \mathrm{~b}$ & $6.5 \mathrm{~b}$ & & $5.4 \mathrm{~b}$ & $5.0 \mathrm{~b}$ \\
7 days & $4.5 \mathrm{~b}$ & $6.0 \mathrm{~b}$ & & $3.6 \mathrm{~b}$ & $4.8 \mathrm{~b}$ \\
Disease CK & $18.0 \mathrm{a}$ & $18.0 \mathrm{a}$ & & $18.0 \mathrm{a}$ & $18.0 \mathrm{a}$ \\
Health CK & $0.0 \mathrm{c}$ & $0.0 \mathrm{c}$ & & $0.0 \mathrm{c}$ & $0.0 \mathrm{c}$ \\
\hline
\end{tabular}

y Culture filtrates of $B$. cereus strains in Luria-Bertani broth were applied to the rhizosphere of lily plants. Different periods after bacterial application, conidial suspension of Botrytis elliptica was atomized onto the abaxial surface of lily leaves.

${ }^{\mathrm{z}}$ Values represent the average number of lesions on a leaf. Each treatment consisted of five plants with five leaves inoculated per plant. Lesion number was recorded 3 days after fungal inoculation. Data in the same column followed by different letters are significantly different $(P=0.05)$. 
than the nonautoclaved ones, showing no significant difference in the lesion number compared with the LB-treated or untreated control leaves. Application of LB medium alone is not capable of decreasing symptom development as the culture filtrates of $B$. cereus strains.

Characterization and comparison of glycine-rich protein genes $L f G R P 1$ and $L s G R P 1$. Plant glycine-rich proteins represent a diverse set of proteins that may interact with RNA in the nuclei, or to be associated with cell walls or membranes (30). A cDNA LsGRP1 sharing homology with several glycine-rich proteins present in the plant extracellular matrix was cloned from Oriental lily cv. Star Gazer and used to show that the expression of LsGRP1 is SA and B. elliptica-inducible (17). Using the primers designed to sequence encoding $L s G R P 1$, an $L s G R P 1$ homolog was successfully amplified from $L$. formosanum and named LfGRP1 (Lilium formosanum glycine-rich protein 1 , accession no. EF681959), which encodes a protein of 135 amino acids. Nucleotide sequences of $L f G R P 1$ and $L s G R P 1$ shared $87 \%$ identity and the deduced amino acid sequences shared $86 \%$ identity. The deduced protein includes an $\mathrm{N}$-terminal region rich in hydrophobic and nonpolar amino acids with a predicted cleavage site of signal peptidase between alanine (Ala-23) and glycine (Gly-24). The mature protein has a predicated molecular weight of $13.72 \mathrm{kDa}$ and is rich in tyrosine (Y) (9.63\%). A cysteine-rich (six in total) carboxyl terminus and a core region composed of glycine stretches, interspersed with tyrosine, proline $(\mathrm{P})$, histidine $(\mathrm{H})$, or asparagine $(\mathrm{N})$ residues, were found. In total, the deduced amino acid sequence contained $28.89 \%$ of glycine residues, with two repeats of YQGGGGG, three repeats of YHNGGG, and one set of YPGGGG sequence, belonging to a type of glycine-rich repeat GGX1X2X3GG (30).

Necrotic lesions caused by B. elliptica on 'Star Gazer' leaves were decreased in plants treated with $B$. cereus strain C1L compared with untreated plants inoculated with the fungus (Fig. 3A). Increased expression of $L f G R P 1$ and $L s G R P 1$ in the leaves of $L$. formosanum seedlings and Oriental lily cv. Star Gazer plants, respectively, was observed 1 day after fungal inoculation and maintained for at least 7 days thereafter (Fig. 3B). In contrast, expression of LfGRPI and LsGRPI in L. formosanum and Oriental lily cv. Star Gazer, respectively, decreased 1 day after application of B. cereus strain C1L. Decreased expression of $L f G R P 1$ and $L S G R P 1$ transcripts was more pronounced in pathogen-inoculated plants beginning 1 day after $B$. elliptica inoculation, regardless of whether bacterial suspensions or culture filtrates were applied (Fig. 3C and D).

\section{DISCUSSION}

L. formosanum, a native species of lily, is used as a landscape plant throughout Taiwan. Outbreaks of leaf and flower blight have devastated L. formosanum planting in Hualien, a county of eastern Taiwan. Based on numerous reports of systemic resistance elicited by rhizobacteria in plants $(1,15,29,40)$, we considered the feasibility of developing the method for reducing the prevalence of Botrytis blight in L. formosanum, especially in landscaped areas. Since good colonization of rhizobacteria in the plant rhizosphere would contribute to their ability to trigger systemic resistance (36), an attempt to isolate beneficial rhizobacteria from healthy stands of L. formosanum was carried out. Among 63 bacterial strains identified, the majority were found to belong to Bacillus or Pseudomonas species, implicating that the rhizosphere of $L$. formosanum is a good habitat for the species belonging to these groups. From the bacterial strains examined for potentials of inducing systemic resistance and effect on the growth of $L$. formosanum seedlings, two B. cereus and two $P$. putida strains were selected for further analysis of their biocontrol activity in this study. All four strains showed effective protection on L. formosanum against $B$. elliptica infection. It was noteworthy that $B$. cereus strain $\mathrm{C} 1 \mathrm{~L}$ consistently exhibited protection in the biocontrol experiments, as well as in greenhouse and field trials on different kinds of lilies.

Systemic resistance triggered by Bacillus species have been observed in many plants (15); however, B. cereus was first reported as a good biocontrol agent in lily by ISR induced through a mechanism that has yet to be determined. Other Bacillus species, such as $B$. amyloliquefaciens, have been screened from lily plants and identified to be suitable for protection by foliar application on Oriental lily against $B$. elliptica $(5,6)$. Through seed microbialization, $B$. cereus was found to reduce disease severity of different kinds of fungal diseases $(34,35)$. The ability of $B$. cereus strain $\mathrm{C} 1 \mathrm{~L}$ to induce systemic resistance in lily was substantially demonstrated herein using a soil drench application method.

$B$. cereus strain $\mathrm{C} 1 \mathrm{~L}$ was able to effectively colonize the $L$. formosanum roots, maintaining populations over $10^{4} \mathrm{CFU} / \mathrm{cm} 10$ days after application. Good colonization is a trait expected to facilitate ISR elicitation by rhizobacteria. For example, many rhizobacteria capable of eliciting ISR against Pseudomonas syringae pv. tomato could effectively colonize tomato roots (36). Other strains of $B$. cereus have been shown to maintain populations on host roots over extended periods. For example, B. cereus UW85 was shown to persist in the rhizosphere of soybean until harvest (10). Thus, it is possible that B. cereus strain C1L is capable of maintaining populations on lily roots for a period longer than 10 days, but such an assumption requires further examination.

According to the results shown in Figure 1, induction of systemic resistance in L. formosanum required a period of 1 day after bacterial application, after which the induced resistance effect could be maintained for at least 10 days, with an optimum observed 4 to 5 days after bacterial application. Effective protection by B. cereus strain C1L was manifested in Oriental lily cvs. Star Gazer and Acapulco, in addition to L. formosanum, suggesting the strain may be capable of inducing systemic resistance over a broad range of plant hosts, similar to B. cereus strain UW85 $(11,12,25,37)$. The application of $B$. cereus strain C1L to other plant species of distant relationship is worthy of investigation.

Studies on ISR-eliciting factors have been approached in Pseudomonas spp. (1). Based on our observation of ISR phenomenon in lily against $B$. elliptica infection, exploration of the nature of elicitors produced by $B$. cereus strain C1L was initiated. Our results implicated that $B$. cereus $\mathrm{C} 1 \mathrm{~L}$ excreted factors that conferred activation of disease suppression in lily. After heat treatment by autoclaving, the timing of disease suppression remained similar to those caused by the original culture filtrates, except for the response in 1-day treatments. These results suggest both $B$. cereus strains $\mathrm{C} 1 \mathrm{~L}$ and $28-9$ produce heat labile factors responsible for early elicitation of ISR observed within 1 day, and heat-stable factor contributing to ISR observed 4 days after treatment. However, it remains unclear whether the eliciting factors produced by B. cereus strains $\mathrm{C} 1 \mathrm{~L}$ and 28-9 are similar. Romeiro et al. (31) reported that $B$. cereus could release macromolecules to trigger systemic disease resistance in tomato. In view of the involvement of lipopeptides and volatile organic compounds of Bacillus species $(24,32)$ in biological control, bacterial determinants responsible for the induction of systemic resistance become an intriguing subject of investigation in biocontrol strains of B. cereus.

LsGRPl has been demonstrated as an SA-dependent, pathogeninducible gene in Oriental lily cv. Star Gazer (17). In L. formosanum, expression of LfGRPI also exhibits pathogen inducibility, implying that similar defense responses might be triggered in different kinds of lilies. Negative regulation of gene expression in response to bacterial treatment has been demonstrated in nonpathogenic Pseudomonas-treated Arabidopsis $(3,41,42)$ and $B$. subtilis-treated tomato and cucumber (23). Likewise, we found that both $L f G R P 1$ and $L s G R P 1$ transcripts decreased after application of strain C1L. Since expression of LfGRPI and LsGRP1 
A

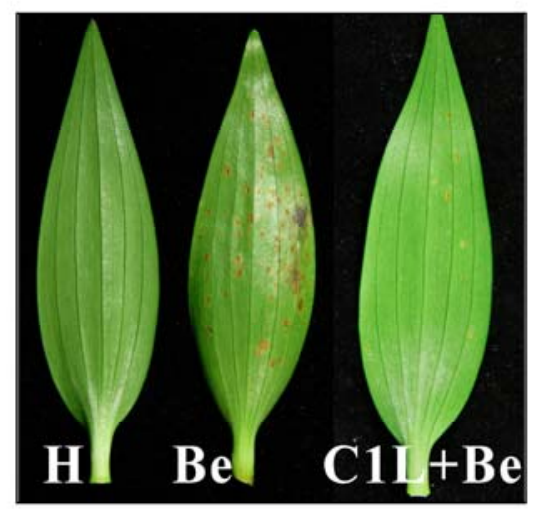

C
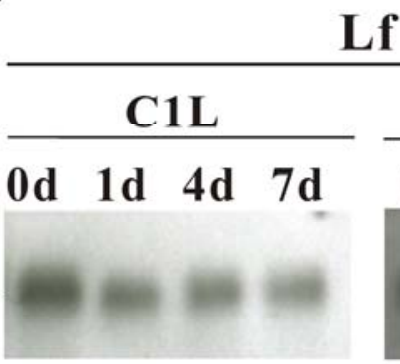

\section{S rRNA \\ 18S rRNA}

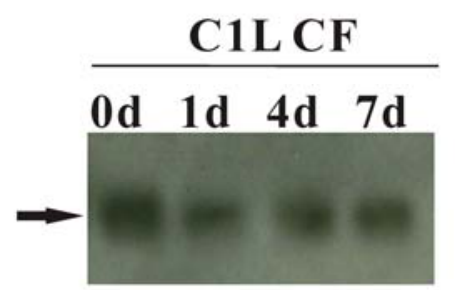

28S rRNA $18 \mathrm{~S}$ rRNA
B

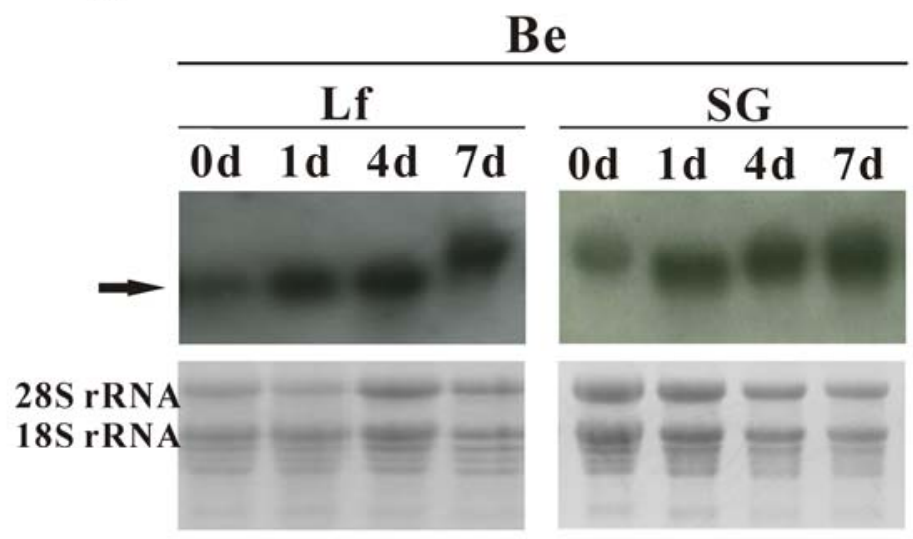

D

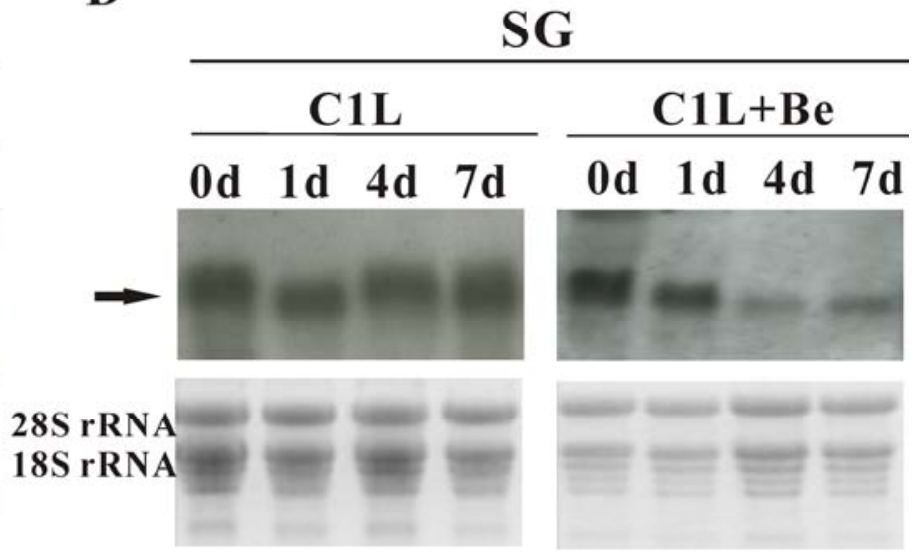

$\mathrm{C} 1 \mathrm{~L} \mathrm{CF}+\mathrm{Be}$
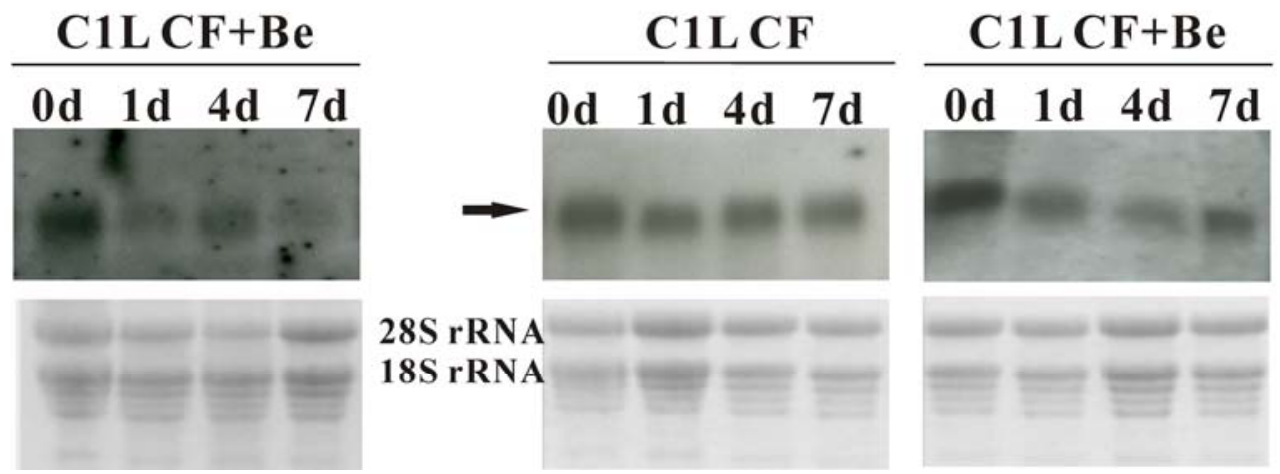

28S rRNA $18 S$ rRNA
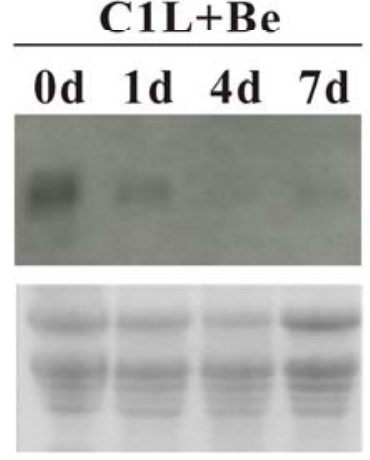

Fig. 3. Northern blot analyses of $L f G R P 1$ and $L S G R P 1$ expression in lily leaves in response to treatment with Bacillus cereus strain C1L. A, Botrytis elliptica was inoculated on 'Star Gazer' leaves 1 day after application of B. cereus strain C1L to the rhizosphere $(\mathrm{C} 1 \mathrm{~L}+\mathrm{Be})$ or without $\mathrm{C} 1 \mathrm{~L}$ treatment $(\mathrm{Be})$. H, healthy leaves without fungal inoculation. Photograph was taken 3 days after fungal inoculation. B, Gene expressions of LfGRP1 in Lilium formosanum (Lf) and LsGRP1 in Oriental lily cv. Star Gazer (SG) were analyzed different days after fungal inoculations. C and D, Gene expressions of $L f G R P 1$ (Lf) and $L s G R P 1$ (SG) in response to the treatment of bacterial suspension $(\mathrm{C} 1 \mathrm{~L})$ or culture filtrate $(\mathrm{C} 1 \mathrm{~L} \mathrm{CF})$ were analyzed different days after treatment with or without subsequent fungal inoculation (Be). The $0 \mathrm{~d}, 1 \mathrm{~d}, 4 \mathrm{~d}$, and $7 \mathrm{~d}$ refers to days after B. elliptica inoculation and C1L alone treatment or after B. elliptica inoculation on C1L-treated plants. The 18S rRNA and 28S rRNA are the references for the amount of total RNA loaded.

were extensively suppressed when $B$. elliptica was inoculated on strain C1L-treated lily plants, we presumed the negative regulation is controlled by a signal transduction pathway induced by B. cereus strain $\mathrm{C} 1 \mathrm{~L}$ that differs from the pathogen-induced SAdirected pathway.

\section{ACKNOWLEDGMENTS}

This study was supported by the Taroko National Park Headquarters, Ministry of the Interior, and the Council of Agriculture, Taiwan, Republic of China. We thank C.-H. Lin and Y.-H. Yang for technical assistance and scientific discussion.

\section{LITERATURE CITED}

1. Bakker, P. A. H. M., Pieterse, C. M. J., and van Loon, L. C. 2007. Induced systemic resistance by fluorescent Pseudomonas spp. Phytopathology 97:239-243.

2. Brooks, A. V. 1980. Lily Diseases and Disorders. Universe Books, New York.

3. Cartieaux, F., Thibaud, M.-C., Zimmerli, L., Lessard, P., Sarrobert, C., David, P., Gerbaud, A., Robaglia, C., Somerville, S., and Nussaume, L. 2003. Transcriptome analysis of Arabidopsis colonized by a plant-growth promoting rhizobacterium reveals a general effect on disease resistance. Plant J. 36:177-188.

4. Chastagner, G. A., and Riley, K. 1990. Occurrence and control of 
benzimidazole and dicarboximide resistant Botrytis spp. on bulb crops in Western Washington and Oregon. Acta Hort. 266:437-445.

5. Chiou, A. L., and Wu, W. S. 2001. Isolation, identification and evaluation of bacterial antagonists against Botrytis elliptica on lily. J. Phytopathol. 149:319-324.

6. Chiou, A. L., and Wu, W. S. 2003. Formulation of Bacillus amyloliquefaciens B190 for control of lily grey mould (Botrytis elliptica). J. Phytopathol. 151:13-18.

7. Doss, R. P., Chastagner, G. A., and Riley, K. L. 1984. Techniques for inoculum production and inoculation of lily leaves with Botrytis elliptica. Plant Dis. 68:854-856.

8. Durrant, W. E., and Dong, X. 2004. Systemic acquired resistance. Annu. Rev. Phytopathol. 42:185-209.

9. Gaffney, T., Friedrich, L., Vernooij, B., Negrotto, D., Nye, G., Uknes, S., Ward, E., Kessmann, H., and Ryals, J. 1993. Requirement of salicylic acid for the induction of systemic acquired resistance. Science 261:754756.

10. Halverson, L. J., Clayton, M. K., and Handelsman, J. 1993. Population biology of Bacillus cereus UW85 in the rhizosphere of field-grown soybeans. Soil Biol. Biochem. 25:485-493.

11. Handelsman, J., Nesmith, W. C., and Raffel, S. J. 1991. Microassay for biological and chemical control of infection of tobacco by Phytophthora parasitica var. nicotianae. Curr. Microbiol. 22:317-319.

12. Handelsman, J., Raffel, S., Mester, E. H., Wunderlich, L., and Grau, C. R. 1990. Biological control of damping-off of alfalfa seedlings with Bacillus cereus UW85. Appl. Environ. Microbiol. 56:713-718.

13. Hsieh, T. F., and Huang, J. W. 1998. Factors affecting disease development of Botrytis leaf blight of lily caused by Botrytis elliptica. Plant Pathol. Bull. 40:227-240.

14. Huang, C. J., Wang, T. K., Chung, S. C., and Chen, C. Y. 2005. Identification of an antifungal chitinase from a potential biocontrol agent, Bacillus cereus 28-9. J. Biochem. Mol. Biol. 38:82-88.

15. Kloepper, J. W., Ryu, C.-M., and Zhang, S. 2004. Induced systemic resistance and promotion of plant growth by Bacillus spp. Phytopathology 94:1259-1266

16. Lu, Y. Y., and Chen, C. Y. 1998. Probenazole-induced resistance of lily against Botrytis gray mold. Plant Pathol. Bull. 7:134-140.

17. Lu, Y. Y., and Chen, C. Y. 2005. Molecular analysis of lily leaves in response to salicylic acid effective towards protection against Botrytis elliptica. Plant Sci. 169:1-9.

18. Lu, Y. Y., Liu, Y. H., and Chen, C. Y. 2007. Stomatal closure, callose deposition, and increase of $L s G R P 1$-corresponding transcript in probenazole-induced resistance against Botrytis elliptica in lily. Plant Sci. 172:913-919

19. MacDaniels, L. H., and Horst, R. K. 1980. Lily Disease Problems in North America. Universe Books, New York.

20. Malamy, J., Carr, J. P., Klessig, D. F., and Raskin, I. 1990. Salicylic acid: a likely endogenous signal in the resistance response of tobacco to viral infection. Science 250:1002-1004.

21. Metraux, J. P., Signer, H., Ryals, J., Ward, E., Wyss, B. M., Gaudin, J., Raschdorf, K., Schmid, E., Blum, W., and Inverardi, B. 1990. Increase in salicylic acid at the onset of systemic acquired resistance in cucumber. Science 250:1004-1006.

22. Migheli, Q., Aloi, C., and Gullino, M. L. 1990. Resistance of Botrytis elliptica to fungicides. Acta Hort. 266:429-436.

23. Ongena, M., Duby, F., Jourdan, E., Beaudry, T., Jadin, V., Dommes, J., and Thonart, P. 2005. Bacillus subtilis M4 decreases plant susceptibility towards fungal pathogens by increasing host resistance associated with differential gene expression. Appl. Microbiol. Biotechnol. 67:692-698.

24. Ongena, M., Jacques, P., Touré, Y., Destain, J., Jabrane, A., Thonart, P. 2005. Involvement of fengycin-type lipopeptides in the multifaceted biocontrol potential of Bacillus subtilis. Appl. Microbiol. Biotechnol. 69:29-38.

25. Osburn, R. M., Milner, J. L., Oplinger, E. S., Smith, R. S., and Handelsman, J. 1995. Effect of Bacillus cereus UW85 on the yield of soybean at two field sites in Wisconsin. Plant Dis. 79:551-556.

26. Park, S. W., Kaimoyo, E., Kumar, D., Mosher, S., and Klessig, D. F. 2007. Methyl salicylate is a critical mobile signal for plant systemic acquired resistance. Science 318:113-116.

27. Pieterse, C. M. J., van Wees, S. C. M., Jon, J., van Pelt, J. A., and van Loon, L. C. 2002. Signaling in rhizobacteria-induced systemic resistance in Arabidopsis thaliana. Plant Biol. 4:535-544.

28. Piyush, P., Sun, C. K., Chandra, P. G., and Dinesh, K. M. 2005. Rhizosphere competent Pseudomonas aeruginosa GRC1 produces characteristic siderophore and enhances growth of Indian mustard (Brassica campestris). Curr. Microbiol. 51:303-309.

29. Ramamoorthy, V., Viswanathan, R., Raguchander, T., Prakasam, V., and Samiyappan, R. 2001. Induction of systemic resistance by plant growth promoting rhizobacteria in crop plants against pests and diseases. Crop Prot. 20:1-11.

30. Ringli, C., Keller, B., and Ryser, U. 2001. Glycine-rich proteins as structural components of plant cell walls. Cell. Mol. Life Sci. 58:14301441.

31. Romeiro, R. S., Lanna, F., Vieira Junior, J. R., Silva, H. S. A., BaracatPereira, M. C., and Carvalho, M. G. 2005. Macromolecules released by a plant growth-promoting rhizobacterium as elicitors of systemic resistance in tomato to bacterial and fungal pathogens. J. Phytopathol. 153:120-123.

32. Ryu, C.-M., Farag, M. A., Hu, C.-H., Reddy, M. S., Kloepper, J. W., and Paré, P. W. 2004. Bacterial volatiles induce systemic resistance in Arabidopsis. Plant Physiol. 134:1017-1026.

33. Shii, C. T. 1983. The distribution and variation of Lilium formosanum Wall. and L. longiflorum Thunb. in Taiwan. Lily Year Book of the North American Lily Society 36:48-51.

34. Silva, H. S. A., Romeiro, R. S., Carrer Filho, R., Pereira, J. L. A., Mizubuti, E. S. G., and Mounteer, A. 2004. Induction of systemic resistance by Bacillus cereus against tomato foliar diseases under field conditions. J. Phytopathol. 152:371-375.

35. Silva, H. S. A., Romeiro, R. S., Macagnan, D., Halfeld-Vieira, B. A., Pereira, M. C. B., and Mounteer, A. 2004. Rhizobacterial induction of systemic resistance in tomato plants: Non-specific protection and increase in enzyme activities. Biol. Control 29:288-295.

36. Silva, H. S. A., Romeiro, R. S., and Mounteer, A. 2003. Development of a root colonization bioassay for rapid screening of rhizobacteria for potential biocontrol agents. J. Phytopathol. 151:42-46.

37. Smith, K. P., Havey, M. J., and Handelsman, J. 1993. Suppression of cottony leak of cucumber with Bacillus cereus strain UW85. Plant Dis. 77:139-142.

38. Sticher, L., Mauch-Mani, B., and Métraux, J. P. 1997. Systemic acquired resistance. Annu. Rev. Phytopathol. 35:235-270.

39. van Loon, L. C. 1997. Induced resistance in plants and the role of pathogenesis-related proteins. Eur. J. Plant Pathol. 103:753-765.

40. van Loon, L. C., Bakker, P. A. H. M., and Pieterse, C. M. J. 1998. Systemic resistance induced by rhizosphere bacteria. Annu. Rev. Phytopathol. 36:453-483.

41. Verhagen, B. W. M., Glazebrook, J., Zhu, T., Chang, H. S., van Loon, L. C., and Pieterse, C. M. J. 2004. The transcriptome of rhizobacteriainduced systemic resistance in Arabidopsis. Mol. Plant-Microbe Interact. 17:895-908.

42. Wang, Y., Ohara, Y., Nakayashiki, H., Tosa, Y., and Mayama, S. 2005. Microarray analysis of the gene expression profile induced by the endophytic plant growth-promoting rhizobacteria, Pseudomonas fluorescens FPT9601-T5 in Arabidopsis. Mol. Plant-Microbe Interact. 18:385396.

43. Ward, E. R., Uknes, S. J., Williams, S. C., Dincher, S. S., Wiederhold, D. L., Alexander, D. C., Ahl-Goy, P., Métraux, J. P., and Ryals, J. A. 1991. Co-ordinate gene activity in response to agents that induce systemic acquired resistance. Plant Cell 3:1085-1094.

44. Wilson, E. H. 1925. The Lilies of Eastern Asia. Dulau and Company, London, UK

45. Yan, Z., Reddy, M. S., Ryu, C.-M., McInroy, J. A., Wilson, M., and Kloepper, J. W. 2002. Induced systemic protection against tomato late blight elicited by plant growth-promoting rhizobacteria. Phytopathology 92:1329-1333.

46. Zehnder, G. W., Murphy, J. F., Sikora, E. J., and Kloepper, J. W. 2001. Application of rhizobacteria for induced resistance. Eur. J. Plant Pathol. $107: 39-50$ 